\title{
Intervenção do profissional de saúde mental em situações de perda e luto no Brasil
}

\author{
Mental Health Professional Intervention in loss and \\ bereavement situations in Brazil
}

\begin{abstract}
RESUMO
Luto é tido pela Psicologia como uma resposta natural e esperada diante de rupturas de vínculos. No entanto, considera-se que 10 a 25\% dos enlutados da população mundial tendem a apresentar reações de intensidade, duração e funcionalidade consideradas comprometidas, desenvolvendo um quadro denominado "luto complicado". Ações preventivas, suportivas e de tratamento foram empreendidas nas últimas duas décadas no Brasil e em outros países. A partir de uma revisão bibliográfica foram identificadas as diferentes possibilidades de intervenções realizadas no Brasil e suas funções específicas no suporte psicológico ao enlutado. Uma pesquisa em bases virtuais de dados entre 2007 e 2017 demonstra que a maioria das intervenções psicológicas com enlutados ali mencionadas aconteceram no setting hospitalar e que os atendimentos em psicoterapia se deram com base em diferentes abordagens teóricas. Observa-se ainda nessas bases uma escassez de artigos sobre a eficácia das intervenções psicológicas com enlutados, aspecto que aponta para a necessidade de ampliação das pesquisas acadêmicas sobre esta questão.
\end{abstract}

Palavras-chave: Psicologia e luto - Processo de luto - Intervenções psicológicas - Luto complicado

\begin{abstract}
Bereavement, according to Psychology, is a natural and expected response when personal bonds are broken. However, it is considered that 10 to $25 \%$ of mourners, worldwide, tend to present reactions of compromised intensity, duration and functionality, developing a condition known as "complicated grief". Preventive and supportive actions, along with treatment, have been developed in the last two decades in Brazil and in other countries. From a bibliographical review, the different possibilities of intervention performed in Brazil and their specific functions in the psychological support to the mourner were identified in this article. A survey on virtual databases between 2007 and 2017 demonstrates that most of the psychological interventions were developed in the hospital setting and that the interventions of psychotherapy with mourners were carried out based on different theoretical approaches. There was also a shortage of articles in this databases evaluating the efficacy of psychological interventions with bereaved males, which leads us to suggest this theme for future academic research about this question.
\end{abstract}

Keywords: Psychology and bereavement - Bereavement - Psychological interventions - Complicated grief

* Doutora em Psicologia Clínica pela Pontifícia Universidade Católica de São Paulo (PUC-SP), Brasil. Cofundadora, professora e supervisora do Instituto de Psicologia Quatro Estações. Organizadora dos livros "Dor silenciosa ou dor silenciada? Perdas e lutos não reconhecidos por enlutados e sociedade" (Polo Books, 2013) e "O Resgate da Empatia: suporte ao luto não reconhecido" (Summus, 2015). Autora de diversos capítulos em livros sobre o tema do luto e consultora ad hoc das revistas de Psicologia da USP e PUC-Campinas e da Gerais: Revista Interinstitucional de Psicologia. CV: http://lattes.cnpq.br/6271486373941085 


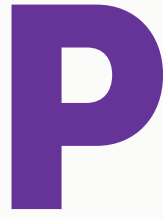
erdas por morte podem mobilizar ampla gama de sentimentos, desorganizando a capacidade de enfrentamento do indivíduo diante da perda, retirando os enlutados da zona de conforto cotidiano. A partir desse pressuposto é possível afirmar que a dor do luto pode ser a mais profunda fonte de sofrimento psicológico para um ser humano. Luto é considerado pela Psicologia como uma resposta natural diante de uma perda e é vivido pela maioria das pessoas diversas vezes ao longo da vida. Apesar dessa visão sobre a naturalidade do processo, a partir de estudos da área da Psicologia realizados nas décadas de 1980 e 1990, o luto passou a merecer atenção e suporte social, considerando-se que a perda de vínculos significativos tenderia a provocar uma ruptura do "mundo presumido"1 dos enlutados. Tal situação é capaz de mobilizar uma crise e desorganização, tanto do funcionamento psíquico do indivíduo como de seu ambiente social. Com base nesta concepção, acredita-se que o luto pode tornar o indivíduo temporariamente vulnerável do ponto de vista psíquico e, sob algumas condições adversas, pode favorecer o adoecimento físico e emocional. O objetivo deste artigo é analisar esse processo, aqui denominado de "luto complicado". Antes, porém, será analisado de que forma o tema vem sendo estudado pela Psicologia.

\section{Uma breve revisão histórica sobre o estudo do luto}

O estudo sobre luto tem ocupado um significativo espaço na comunidade científica internacional desde o século XVII, quando reações de pesar foram descritas como sintoma e causa principal da melancolia pelo médico Robert Burton, em sua publicação The Anatomy of Melancholie, datada de 1621 (Parkes, 2001). O luto em massa, em razão da I Guerra Mundial, trouxe para o cenário científico da Europa uma grande preocupação com os sintomas de pesar. Com base em suas observações clínicas, Freud publicou o texto Luto e Melaconlia, em 1917, cunhando o termo "trabalho de luto" e inaugurando definitivamente o tema do luto como objeto de estudo científico (Freud, 1953[1917]).

A Segunda Guerra Mundial alavancou outros estudos relevantes, dentre eles, Lindemann (1944) esboçou uma definição sobre luto normal, bem como inaugurou o termo "luto antecipatório" para descrever reações de pesar diante da iminência da perda, como observado em esposas de soldados que foram convocados para o campo de batalha. Neste cenário europeu devastado pela guerra, a Organização Mundial de Saúde - OMS - também se mostrou preocupada com os efeitos da orfandade nas crianças, cujos pais haviam falecido em combate, e cujas mães passaram a trabalhar e deixar seus filhos sob cuidados de estranhos nas creches residenciais. Para entender melhor os efeitos daquele luto no desenvolvimento infantil, o psiquiatra John Bowlby, pesquisador da Clínica Tavistock em Londres, foi convidado pela OMS para desenvolver uma pesquisa rigorosa e sistemática de observação das reações de

1 Parkes definiu o conceito de "mundo presumido" como o único mundo que o indivíduo conhece e se reconhece, e inclui tudo o que ele sabe ou pensa saber. Este termo engloba o que o indivíduo pensa sobre o passado, suas expectativas para o futuro, seus valores, crenças e planos. Segundo o autor, estes aspectos são abalados diante de uma perda e uma nova concepção de mundo se faz necessária no processo de adaptação (Parkes, 1971). 
separação a aproximação destas crianças em relação às suas figuras de cuidado principais. Este estudo serviu como fundamentação para algumas ações sociais na Inglaterra; entre elas, a lei de licença maternidade e por sua relevância foi publicado na Inglaterra em 1953, sob o título The nature of child's tie to its mother. ${ }^{2}$ Este estudo foi um grande passo no desenvolvimento da Teoria do Apego, que tinha o fenômeno da separação e do luto como tema central para a compreensão do papel do apego no desenvolvimento humano, em especial, quando experimentados na primeira infância.

Na década de 1960, o psiquiatra britânico Colin Parkes também se destacou no estudo dos vínculos e nos efeitos de sua ruptura. Ele aprofundou-se no estudo e observação clínica do luto adulto, com base na mesma teoria desenvolvida pelo colega John Bowlby. (Parkes, 1998). Philippe Ariés (1977a e 1977b) destacou o tabu em torno da morte, ditado pelo excessivo apego à vida produtiva, tão característico de nossa civilização industrial, que aos poucos gerou um temor diante da ideia de morrer. O autor aponta que a atitude diante da morte sofreu mudanças significativas no século XX; uma delas foi a tendência de ocultamento do moribundo da real gravidade de seu estado. $O$ antigo costume de morrer em casa foi substituído pela morte no hospital; a assistência familiar que o moribundo tinha foi substituída por cuidados médicos. A morte passou a ser temida e as formalidades para enterrar o corpo passaram a ser consideradas nesta época como desritualizadas e cumpridas rapidamente.

O luto também foi compreendido a partir de uma perspectiva da construção de significado (Nadeau, 1997; Neimeyer, 2001) e alguns estudos apontaram a possibilidade de manutenção de vínculos contínuos, em oposição à necessidade de desligamento da pessoa falecida. (Klass e Walter, 2001). Stroebe e Schut desenvolveram um modelo de compreensão dos fenômenos presentes no processo de luto (Stroebe, 2008; Stroebe, Hansson, Schut, 2008; Stroebe e Schut, 1999 e 2001): o Modelo do Processo Dual, relevante não apenas para pesquisas como em sua aplicabilidade na prática clínica. Este modelo propõe uma revisão das concepções teóricas sobre o processo do luto, ao identificar dois tipos de fatores estressores - orientados para a perda e para a restauração - e ao considerar a existência de um processo dinâmico e regulador do enfrentamento, pela oscilação por meio da qual o enlutado pode às vezes confrontar, às vezes evitar as diferentes tarefas do luto (definidas por este modelo como "trabalho de luto" e "restauração"). Este modelo postula que o enfrentamento adaptativo é composto por confrontação/evitação da perda, em equilíbrio com as necessidades de ajustamento à vida que segue.

Desde a década de 1980, muitas abordagens teóricas desenvolveram conceitos em torno do fenômeno do luto e propostas interventivas com enlutados, dentre elas: Psicanálise, Fenomenologia, Teoria Cognitiva-Comportamental, Sistêmica, Psicologia Social, entre outras, que se dedicaram a compreender o fenômeno do luto a partir de diferentes enfoques. A abordagem da Teoria do Apego (Bowlby, 1969[2002], 1973[2004a], 1980[2004b], 1982 e 1988) tem sido muito utilizada no cenário acadêmico internacional, como fundamentação para a intervenção com enlutados e para formação dos profissionais envolvidos nesta prática. Esta

2 Publicado no Brasil com o título Cuidados Maternos e Saúde Mental (Bowlby, 1981). 
abordagem diferencia-se das analíticas, que enfatizam o foco exclusivo no mundo intrapsíquico, pois apoia-se tanto no referencial biológico, com base em suas influências etológicas, como no intrapsíquico e social para compreender o fenômeno. Esta teoria nasceu da psicanálise, mas transbordou para outros referenciais teóricos, desenvolvida com base na observação direta do comportamento humano diante de situações de rupturas de vínculo. Esta abordagem destaca a importância do sentimento de proteção e reasseguramento diante da ameaça que a distância de uma figura de apego evoca, seja pela separação ou por uma ruptura definitiva. É uma teoria que oferece uma compreensão consistente sobre as reações humanas à perda, bem como sobre as condições de enfrentamento do luto. Acrescente-se o dado de que fornece conceitos para entender as condições adaptativas necessárias ao processo de luto para cada indivíduo, considerando aspectos universais e individuais. É tida como extremamente útil e eficaz nas intervenções desenvolvidas com foco no luto (Parkes, 1981 e 2009; Kissane e Parkes, 2014; Stevenson-Hinde, Marris e Parkes, 1991; Schut e Stroebe, 2005). Por esta razão, este artigo tem como principal referência teórica a "Teoria do Apego", para tratar de conceitos relacionados ao fenômeno do luto.

As pesquisas e intervenções com enlutados começaram a ganhar força e sistematização no Brasil desde a década de 1980, mas foi no fim da década de 1990 que dois polos acadêmicos iniciaram estudos e pesquisas nesta área, com enfoque em Psicologia. A docente da PUC/SP Profa. Dra. Maria Helena Pereira Franco empreendeu seus estudos de pós-graduação com enfoque na psicoterapia com enlutados (Bromberg, 1995; Franco, 2010 e 2017). Desde então abriu portas para o desenvolvimento de pesquisas e intervenções com esta população, culminando com a inauguração do LELu - PUC/SP (Laboratório de Estudos e Intervenções de Luto), fundado em 1996, com o objetivo de realizar pesquisas e atendimento psicológico comunitário. Além daquela universidade, a USP iniciou ações de caráter acadêmico e posteriormente comunitário, por meio do LEM - Laboratório de Estudos da Morte, coordenado pela Profa. Dra. Júlia Kovács (Kovács, 1996). Entre outras ações, alguns membros do LELu fundaram em 1998, o 4 Estações Instituto de Psicologia, instituição privada de ensino e prática com sede em São Paulo, com inauguração de sua clínica social em 2007. Estas instituições realizaram inúmeras ações comunitárias e voluntárias focadas em luto, bem como são responsáveis pela formação técnica de um número crescente de profissionais de saúde mental, desde o fim da década de 1990. Destes polos de intervenção e treinamento surgiram outros de natureza privada por todo país. Eventos científicos nacionais e internacionais foram organizados, e clínicas sociais se estabeleceram, oferecendo suporte especializado para enlutados sem possibilidade de acesso a serviços particulares. O luto passou a ser debatido em sala de aula, e atualmente tornou-se tema opcional em alguns cursos de graduação de Psicologia (ex: PUC/SP, Mackenzie/SP, USP, UFRJ) e em muitos cursos de pós-graduação em Psicologia Hospitalar e Cuidados Paliativos (ex: Hospital HCor/SP, Hospital Albert Einstein/SP, Hospital Sirio Libânes/SP, Hospital Oswaldo Cruz/ SP, Santa Casa de São Paulo, entre outros).

No que tange ao cenário internacional, a Profa. Dra. Maria Helena Pereira Franco também desempenhou relevante papel articulando os estudos e práticas clínicas do Brasil 
com pesquisadores e psicoterapeutas de todos os continentes. Desde 1999 ela é membro da IWG - Internacional Work Group on Death, Dying and Bereavement, organização que agrega pesquisadores de todo o mundo, com reuniões a cada 18 meses, para grupos de discussão e colaboração intercultural, voltadas ao desenvolvimento e sistematização teórica e protocolos de intervenção focados em situações de perda. Em 2007, o Brasil sediou um destes encontros. Nesta ocasião, muitos pesquisadores brasileiros conheceram e compartilharam com autores internacionais suas experiências práticas e seus resultados de pesquisas, além de reflexões sobre as especificidades culturais que tangenciam as experiências de luto.

Diante deste histórico, é fundamental uma reflexão em torno do que tem sido feito a partir da produção teórica referente ao tema do luto e como tais ações se estruturam no Brasil. Este artigo visa investigar e explorar as distintas possibilidades de intervenções especializadas em luto realizadas no Brasil na última década, considerando diferentes objetivos nas ações empreendidas para suporte psicológico ao enlutado, seja focando na prevenção do luto complicado ou no tratamento, quando tal condição se estabelece.

Para fomentar esta análise, foi realizada uma pesquisa bibliográfica a partir de buscas nas seguintes bases virtuais de dados: Periódicos Eletrônicos em Psicologia (PePSIC) e Scientific Eletronic Library Online (Scielo), com o objetivo de identificar e analisar as intervenções psicológicas oferecidas para enlutados no Brasil, publicadas em artigos científicos brasileiros entre 2007 e 2017. Foram encontrados 68 artigos na base PePSIC, usando a palavra-chave "luto". Dentre estes, 13 estavam relacionados diretamente à apresentação de intervenções psicológicas com enlutados, enquanto na base Scielo foram encontrados 219 artigos científicos sobre luto. Destes, 09 eram referentes à discussão de intervenções com enlutados. Portanto, um total de 22 artigos foi submetido ao levantamento e análise das informações coletadas.

\section{Luto e luto complicado: quando e por quê intervir?}

Em estudos epidemiológicos recentes, Schut e Stroebe (2005, p. 141) e Lombardo et al (2014) apontam resultados semelhantes, que indicam que a maioria das pessoas se ajusta adequadamente à perda de alguém próximo sem a necessidade de intervenção profissional. Contudo, 10 a 25\% destas pessoas experimentariam variações de luto complicado. Em ambos os estudos, os autores consideraram a população geral e investigaram vários fatores que teriam influenciado o enfrentamento do luto, como: relacionados à perda (tipo de perda, de vínculo com a pessoa falecida, condições físicas e psicossociais do enlutado) e fatores associados às caraterísticas da vida e personalidade dos sujeitos, bem como as condições do suporte social recebido na ocasião e após a perdas. Na perspectiva da Psicologia, quando uma pessoa morre, considera-se que o evento da morte pode ser impactante para o sistema familiar e social preexistente. Portanto, o número de enlutados em cada situação de perda pode superar a quantidade dos membros do núcleo familiar, incluindo outras pessoas com vínculos afetivos com a pessoa falecida. Do ponto de vista sistêmico, consideram-se clinicamente afetadas todas 
as pessoas vinculadas à pessoa falecida, o que não se restringe aos familiares consanguíneos.

A partir da aplicação das estatísticas que constam em estudos epidemiológicos citados (Schut \& Stroebe, 2005, p. 141; Lombardo et al, 2014), considerando apenas as taxas brutas de mortalidade no Brasil em 2015, ${ }^{3}$ que totalizam 6,08 por mil habitantes, é possível afirmar a importância da oferta de serviços de saúde públicos e privados, direcionados ao cuidado dos processos de luto comprometidos e suas reverberações. Essas intervenções podem ser orientadas como um campo de atenção preventiva ou, ainda, em atenção aos riscos de diversas doenças de ordem física e psicológica, quando sob certas condições desfavoráveis de enlutamento. Este artigo visa identificar as distintas possibilidades de intervenções especializadas em luto, considerando os diferentes objetivos nas ações dirigidas ao suporte psicológico do enlutado, seja com foco na prevenção do luto complicado ou no tratamento, bem como refletir sobre até que ponto os estudos sobre o tema têm enfocado a eficácia de tais intervenções.

Lichtenthal et al (2015), em um estudo multicêntrico com 120 pais enlutados pela morte de um filho com câncer, cujo período de luto oscilou entre 6 meses e 6 anos após a perda, apontaram que $41 \%$ dos pais enlutados usaram serviços de saúde mental (terapia, intervenção medicamentosa e grupo de apoio) até dois anos após a perda. Este estudo destaca a percepção dos enlutados com relação às modalidades de suporte. A ajuda mais frequentemente utilizada foi a psicoterapia. No entanto, $36 \%$ dos pais suspenderam o processo terapêutico por entenderem que não ajudava devido à dificuldade de falar sobre a dor. Segundo esta pesquisa, este argumento também foi apresentado por $64 \%$ dos entrevistados para justificar sua dificuldade em acessar ajuda, enquanto 60\% comentaram que era difícil encontrar ajuda especializada. Infelizmente, o estudo não explorou os motivos pelos quais tais serviços não foram acessados, apesar de existirem. Nas conclusões, os autores sugerem uma revisão da necessidade de treinamento específico dos profissionais que já oferecem este tipo de intervenção, sem o devido preparado para tanto. Os autores também empreendem uma reflexão crítica sobre a forma como ocorre a oferta e divulgação dos serviços existentes. Por fim, eles concluem que não são devidamente direcionados ao público alvo.

Em termos de referências internacionais, não podemos deixar de citar o Dr. Colin Murry Parkes, psiquiatra Consultor Honorário do St. Christopher's Hospice e do St Joseph's Hospice, ${ }^{4}$ ambos em Londres, Inglaterra. Como psiquiatra supervisor no St Christopher's Hospice, desde sua concepção em 1966, estabeleceu o primeiro serviço de atendimento para luto, e desenvolveu as primeiras avaliações sistemáticas dos cuidados em hospice. Foi presidente e atualmente é presidente vitalício de Cruse: Bereavement Care, organização que cuida de

3 IBGE. Taxas Brutas de Mortalidade no Brasil em 2015. Disponível em <http://brasilemsintese.ibge.gov.br/ populacao/taxas-brutas-demortalidade.html>. Acesso em 11/01/2017.

4 Hospices são instituições voltadas para a assistência de pacientes com doenças avançadas, e fora de possibilidades de cura, que se encontram em franca expansão entre os profissionais de saúde em todo o mundo. Este serviço surgiu no final da década de 1960 na Inglaterra e envolve um trabalho com equipe multidisciplinar orientado para um cuidado médico especializado no manejo e alívio da dor, suporte emocional e espiritual visando atender as necessidades e desejos do paciente. Vale ressaltar que o suporte é também estendido para os familiares do paciente. Somente na Inglaterra, mais de 200.000 pessoas com doenças fora de possibilidades de cura e seus familiares são atendidas em mais de 200 hospices por todo o país a cada ano. Cf. <https://www.hospiceuk.org>. Acesso em 29/05/17. 
pessoas enlutadas na Inglaterra. Trabalhou como consultor em ações para atendimento a diversas tragédias. A convite da UNICEF, estabeleceu o Programa de Recuperação de Trauma em Ruanda, em 1995. A convite do governo britânico, ajudou a estabelecer um programa de apoio em Nova lorque às famílias britânicas que estavam presentes e foram afetadas pelos ataques terroristas de 11/09/2001. Em abril de 2005 foi enviado pela organização Help-theHospices, com Ann Dent, para a Índia, para avaliar as necessidades psicológicas das pessoas enlutadas em decorrência do tsunami. Seus estudos e publicações recentes têm abordado o luto traumático (em especial por mortes violentas e pelo ciclo da violência) e as raízes do apego na infância e suas consequências. Em junho de 1996 recebeu da Rainha Elizabeth II a Ordem do Império Britânico, pelos serviços prestados aos enlutados. Sua trajetória pioneira e internacional configura suas publicações como referências indispensáveis para quem atua na área. (Parkes, 1981, 2015c[1996], 1998, 2009, 2014, 2015a, 2015b).

Segundo Parkes (1981, 2015a e 2015b), os estudos centrados na eficácia dos serviços de suporte psicossocial para enlutados apontam que a maioria se beneficia de aconselhamento. Vale esclarecer que o aconselhamento é um tipo de intervenção psicossocial, que pode ser realizada por psicólogos ou voluntários treinados. Neste atendimento há uma oferta de espaço para expressão de pesar, validação do sofrimento, informações acerca dos sintomas esperados num processo de luto, e auxilia o enlutado no enfrentamento das adaptações psicossociais necessárias e inevitáveis nos primeiros meses após a perda.

Os resultados apontados por Parkes (1998, 2015a e 2015b) podem ser justificados pelo fato de que a maior parte da população mundial apresenta reações de luto transitórias, e apenas a minoria necessita de ajuda para além do suporte familiar e social. Sobre essa minoria, Parkes (2015a e 2015b) ressalta que não existe uma única fórmula de ajuda. Destaca que passados vinte anos de estudos e intervenções sistematizadas pelo mundo, atualmente há melhores condições de oferta de ajuda efetiva e especializada, abrangendo uma variedade de métodos e técnicas para as diferentes demandas no processo de enfrentamento da perda e do luto.

As reações diante de uma perda podem ocorrer de distintas maneiras e não devem ser consideradas universais e padronizadas. Cada indivíduo terá um tipo de resposta sustentada por diversas variáveis: desde suas respostas instintivas diante da ameaça e medo mobilizados pela perda, abrangendo suas condições pessoais de história de vida, suporte social, contexto cultural, até as características do relacionamento perdido e das condições da perda. Portanto, o espectro considerado saudável de reações à perda é amplo, pois se refere às condições individuais de ajustamento, ainda que possam ser julgadas pela opinião pública como inadequadas ou equivalentes a uma desordem mental. É neste sentido que, ao considerar certas reações intensas e prolongadas como indicadores de complicação sem analisar o contexto, é possível incorrer em equívoco por caracterizar determinadas vivências de luto como complicadas. Nos casos de pais enlutados, por exemplo, é frequente e esperado que as respostas permaneçam intensas e prolongadas por mais de um ano. Em estudo recente, as pesquisadoras da Curtin University, na Austrália, Lauren Breen, Emma Pennnan, Holly Prigerson e Lauren Hewitt (2015) realizaram uma inovadora pesquisa multicultural com 348 adultos entre 
18 e 80 anos, que falavam inglês, residentes de diferentes países. O objetivo era investigar a percepção da opinião pública sobre as reações de luto. A pesquisa consistia na apresentação de uma vinheta descrevendo uma pessoa enlutada pela morte da esposa. Os participantes eram questionados sobre suas expectativas em relação às reações do enlutado fictício. Em seguida, os entrevistados foram questionados sobre quais reações de luto poderiam ser consideradas características de desordens mentais e porquê. Os resultados apontaram que 74\% declararam que luto pode ser considerado uma desordem mental e que os sujeitos entrevistados apresentam tal percepção a partir da comparação com suas experiências pessoais de perda, o que significa que tendem a julgar inadequadas reações adversas às experimentadas.

Os resultados deste estudo (Breen, Pennnan, Prigerson e Hewitt, 2015) podem ser utilizados para refletir sobre o estigma presente em torno do luto e sobre seu impacto nas normas públicas, na compaixão e empatia com o enlutado, na oferta de suporte social necessário, bem como em relação à forma como tal percepção interfere e influencia a avaliação diagnóstica dos profissionais de saúde que atuam com os enlutados. Portanto, é imperativa a realização de pesquisas e publicações de artigos e livros dirigidos à população em geral acerca de esclarecimentos sobre as reações de luto que não seriam indicativos de transtorno mental. Ao contrário, tratam-se de reações esperadas, em determinados contextos: são temporárias e respostas naturais a um evento. Tais esclarecimentos são fundamentais para uma discussão acerca da inclusão do luto em manuais de diagnóstico psiquiátrico, assim como para profissionais de saúde. A polêmica em torno destas decisões foi tratada em artigo publicado por Parkes na Revista Omega (Parkes, 2005-2006a) como resultado do grupo de discussões realizado num Simpósio sobre Luto Complicado na IWG (Internaticonal Work Group). Neste texto, Parkes e demais colaboradores, entre elas Maria Helena Pereira Franco, apontaram a vantagem da inclusão do luto no DSM $V^{5}$, como meio de fomentar o acesso da população carente aos tratamentos que fossem necessários e que passariam a ser reconhecidos e acatados pelo sistema público de saúde a partir de sua incorporação neste manual. No entanto, apontaram algumas restrições a esse processo de classificação dos sintomas frente ao risco de eventuais excessos de patologização dos lutos ou, ainda, pelo risco de exclusão de algumas complicações particulares deste processo de perda.

O luto é um processo multidimensional de reações a uma perda concreta (morte) ou simbólica (como em casos de separação ou desaparecimento), validado ou não pela sociedade em que o indivíduo está inserido (Casellato; Franco; Mazorra e Tinoco, 2009). Segundo Parkes (1998), o processo de luto é uma condição dinâmica, não linear, que não culmina no estado anterior ao luto. Por tais características, pode ser uma condição crítica, de instabilidade psíquica, por ser decorrente das condições prévias e adaptativas após a perda.

Por ser um processo, o luto é dinâmico e conta com ampla variedade de reações por ele desencadeadas, reflete uma situação de crise mobilizada pela ruptura com o mundo

5 DSM V: Manual de Diagnóstico e Estatística de Transtornos Mentais, 5a edição. Trata-se de um manual diagnóstico e estatístico elaborado pela Associação Americana de Psiquiatria para definir critérios de diagnóstico de transtornos mentais, sendo utilizado por profissionais de saúde mental. Desde o DSM-I, criado em 1952, esse manual tem sido uma das bases de diagnósticos de saúde mental mais usadas no mundo. 
presumido e os desafios da adaptação após a perda. Tais desafios envolvem uma transformação da percepção de si e do mundo à sua volta (Parkes, 1998). O mundo externo molda este processo, seja pelos parâmetros socioculturais (ex: expectativas sobre reações pública de pesar) e religiosos (ex: autorização para expressão do sofrimento) ou, ainda, pela dinâmica familiar em questão (ex: condições da comunicação no sistema familiar e os papéis assumidos por cada membro). Porém, é também do mundo interno que o enlutado se valerá para enfrentar seu sofrimento, uma vez que a crise provocada pela perda pode gerar uma quebra de suas defesas psíquicas, bem como das condições previamente desenvolvidas de adaptação ao ambiente psicossocial. Assim, é possível uma ruptura com seu senso de pertencimento e reasseguramento, condição fundamental para o equilíbrio psíquico, na medida em que desafia o aprendizado e a convivência com a dor, para um ajustamento ao novo cenário imposto pela perda (Stroebe \& Schut, 1999; Neymeyer, 2001). Cada enlutado terá sua própria percepção da experiência da perda e do luto, que será multideterminada por todos os parâmetros mencionados.

Diante do desafio complexo do luto, o indivíduo se fragiliza e o suporte social tornase fundamental para enfrentar tal experiência. Em geral, o enlutado conta com o apoio de sua comunidade e na maioria das situações, este suporte é efetivo e dispensa qualquer intervenção complementar, como apontam as pesquisas de Parkes (1998), Lombardo e et al (2014) e Schut \& Stroebe (2005). No entanto, há situações nas quais o suporte familiar e comunitário não é suficiente para acolher o sofrimento do enlutado, a fim de garantir um suporte para o enfrentamento do luto, entre elas (Doka, 2002 a, 2002b; Casellato, 2013, 2015): a) quando a comunidade julga, estigmatiza ou não sanciona a perda, o luto e/ou as reações do enlutado. Como exemplo, as relações não reconhecidas socialmente, como dos amantes, de ex-maridos e ex-esposas, de suicídio; b) quando a comunidade está muito afetada pela perda, e as reações de luto tornam-se uma sobrecarga para o processo empático com o enlutado (ex: perdas coletivas em uma mesma comunidade, como em acidente aéreo); c) quando as reações do enlutado inibem ou impedem um suporte social efetivo. Por exemplo: uma pessoa que não expressa publicamente seu pesar; d) quando o enlutado já apresenta sinais de luto complicado e o suporte social torna-se insuficiente (ex: enlutados com transtornos psiquiátricos prévios à perda ou enlutados com sintomas de intensidade moderada e disfuncionais muito tempo após a perda); e) quando o suporte social é precário. (por exemplo: enlutado isolado socialmente, com rede social ausente ou com restrita oferta de suporte).

Nessas condições é possível considerar que há risco de comprometimento do processo do luto; o que justificativa as intervenções de ordem preventivas e suportivas. O luto complicado é avaliado como um prolongamento do processo normal de luto, que pode produzir efeitos negativos na saúde física e mental, influenciando significativamente a qualidade de vida do enlutado e de seu entorno familiar e comunitário. Um estudo empreendido na Alemanha (rural e urbana) com 2.520 sujeitos indicou que a prevalência de luto complicado na população geral variou de 3,7 a 4,8\% (Kersting, Brahler, Glaesmer e Wagner, 2011). A prevalência na população enlutada estudada contou com variação entre $10 \%$ e $25 \%$. Este estudo abrangeu grupos de todas as idades, de ambos os gêneros e uma ampla variedade de grupos de enlutados (pela 
morte de um filho por suicídio, por morte repentina, por perda esperada).

Em artigo já citado (Casellato, Franco, Mazorra e Tinoco, 2009), foi efetuada revisão de recentes estudos multiculturais sobre luto complicado, em que inicialmente se considerava a duração e intensidade dos sintomas como únicos critérios para avaliar a evolução do luto. Além disso, entendia-se luto como um processo que findava na medida em que haveria uma recuperação completa da pessoa enlutada, ainda que sem retorno à mesma condição anterior ao evento que gerou o luto. Assim, a avaliação era realizada a partir da condição de adaptação e redução de sintomas, que representavam uma melhora do funcionamento do indivíduo.

Segundo Parkes (1998) e Rando (1993), o luto é considerado complicado quando suas reações se dão de modo diverso ao esperado ou estão ausentes. Entende-se como esperadas, diante das normas socioculturais presentes em cada comunidade. Portanto, considera-se a contextualização da perda e a subjetividade da expressão dos enlutados no diagnóstico para o desenvolvimento de intervenções adequadas a cada situação (Casellato, Franco, Mazorra e Tinoco, 2009).

\section{Sobre o suporte adequado às especificidades do luto}

Schut e Stroebe (2005-2006, p. 141) apontam que, atualmente, intervenções potencialmente viáveis em contextos socioculturais ocidentais incluem variadas ações de suporte: desde equipes de emergência visitando famílias enlutadas poucas horas após o óbito, grupos de autoajuda, programas de educação para enlutados, tratamentos envolvendo informações e emoções compartilhadas em grupo, psicoterapia breve de grupo, hipnoterapia à terapia dinâmica. Para facilitar a diferenciação das intervenções quanto ao objetivo, função e limite de alcance, os autores formularam os conceitos de intervenções primárias, secundárias e terciárias adotados neste artigo, que foram sistematizadas no quadro abaixo:

Quadro 1: Os diferentes tipos de intervenções junto aos enlutados, segundo Schut e Stroebe

\begin{tabular}{|c|l|l|l|}
\hline SUPORTES & \multicolumn{1}{|c|}{$\begin{array}{c}\text { INTERVENÇÕES } \\
\text { PRIMÁRIAS }\end{array}$} & $\begin{array}{c}\text { INTERVENÇÕES } \\
\text { SECUNDÁRIAS }\end{array}$ & $\begin{array}{c}\text { INTERVENÇÕES } \\
\text { TERCIÁRIAS }\end{array}$ \\
\hline PARA QUEM? & $\begin{array}{l}\text { Todas as pessoas que tenham } \\
\text { experimentado a perda de al- } \\
\text { guém próximo e significativo. }\end{array}$ & $\begin{array}{l}\text { Para enlutados com alto } \\
\text { risco de complicações no } \\
\text { luto (ex: perdas por homicí- } \\
\text { dio, perdas múltiplas ou sob } \\
\text { circunstâncias traumáticas). }\end{array}$ & $\begin{array}{l}\text { Para enlutados que estão expe- } \\
\text { rimentando complicações no } \\
\text { processo de luto (ex: sintomas } \\
\text { depressivos persistentes, patolo- } \\
\text { gias pré-existentes) }\end{array}$ \\
\hline $\begin{array}{c}\text { QUEM PODE } \\
\text { INTERVIR? }\end{array}$ & $\begin{array}{l}\text { Voluntários treinados, profis- } \\
\text { sionais de saúde e educação. }\end{array}$ & $\begin{array}{l}\text { Profissionais de saúde men- } \\
\text { tal ou voluntários treinados. }\end{array}$ & Psicólogos e psiquiatras. \\
\hline
\end{tabular}




\begin{tabular}{|c|c|c|c|}
\hline OBJETIVOS & $\begin{array}{l}\text { Informar, validar a expressão } \\
\text { do pesar, compartilhar a dor e } \\
\text { promover organização cogni- } \\
\text { tiva diante do stress desenca- } \\
\text { deado pela perda. }\end{array}$ & $\begin{array}{l}\text { Validar a expressão do pe- } \\
\text { sar, oferecer suporte, dimi- } \\
\text { nuir o isolamento social e } \\
\text { promover o alívio dos fato- } \\
\text { res de risco já instalados }\end{array}$ & $\begin{array}{l}\text { Informar, validar a expressão } \\
\text { do pesar, compartilhar a dor, } \\
\text { organização cognitiva em torno } \\
\text { do estresse gerado pela perda, } \\
\text { fortalecimento dos recursos de } \\
\text { enfrentamento, oferecer base } \\
\text { segura para o enfrentamento } \\
\text { de uma crise num contexto de } \\
\text { importante fragilidade psíquica, } \\
\text { foco na narrativa e fortaleci- } \\
\text { mento da autoestima, foco no } \\
\text { comprometimento direcionado } \\
\text { ao enfretamento do pesar e da } \\
\text { adaptação à vida após a perda e } \\
\text { fortalecimento da autoestima. }\end{array}$ \\
\hline $\begin{array}{l}\text { AÇÕES E IN- } \\
\text { TERVENÇÕES }\end{array}$ & $\begin{array}{l}\text { Folhetos informativos, progra- } \\
\text { ma de educação, palestras de } \\
\text { caráter informativo sobre o } \\
\text { processo de luto, grupos infor- } \\
\text { mativos temáticos (ex: familia- } \\
\text { res que estejam vivendo luto } \\
\text { antecipatório, perdas de filhos, } \\
\text { perdas de irmão, familiares que } \\
\text { perderam por suicídio), grupos } \\
\text { de autoajuda, entrevistas em } \\
\text { rádio e TV, informação veicu- } \\
\text { lada pela internet, publicações } \\
\text { dirigidas aos enlutados e aos } \\
\text { profissionais de saúde e edu- } \\
\text { cação. }\end{array}$ & $\begin{array}{l}\text { Grupos de autoajuda, acon- } \\
\text { selhamento em grupo e } \\
\text { individual, psicoterapia in- } \\
\text { dividual focal e breve (esta } \\
\text { última deve ser conduzida } \\
\text { apenas por psicólogos ou } \\
\text { psiquiatras). }\end{array}$ & $\begin{array}{l}\text { Técnicas de tratamento psico- } \\
\text { terapêutico e intervenção me- } \\
\text { dicamentosa (se indicado por } \\
\text { avaliação da psicodinâmica do } \\
\text { indivíduo no contexto do luto). }\end{array}$ \\
\hline QUANDO & $\begin{array}{l}\text { Pré e pós evento da perda (nos } \\
\text { primeiros meses após a perda) }\end{array}$ & $\begin{array}{l}\text { Pré e pós evento da perda } \\
\text { (até o primeiro ano após a } \\
\text { perda) }\end{array}$ & $\begin{array}{l}\text { Pós perda (nos primeiros anos } \\
\text { após a perda) }\end{array}$ \\
\hline $\begin{array}{l}\text { FUNÇÃO PRI- } \\
\text { MÁRIA }\end{array}$ & $\begin{array}{l}\text { Prevenção e suporte psicoló- } \\
\text { gico }\end{array}$ & $\begin{array}{l}\text { Prevenção e suporte psico- } \\
\text { lógico }\end{array}$ & $\begin{array}{l}\text { Tratamento psicológico e psi- } \\
\text { quiátrico (este último, quando } \\
\text { necessário). }\end{array}$ \\
\hline
\end{tabular}

Fonte: Adaptado de Schut e Stroebe, 2005-2006, p. 141.

A diferenciação dos tipos de intervenções sugerida pelos autores Schut e Stroebe (2005) pode oferecer uma condição que se considere eficiente e objetiva na oferta de suporte psicossocial aos enlutados, tendo como premissa que cada um destes teria uma reação única diante de cada perda e, consequentemente, o profissional de saúde mental possa ter clareza sobre qual intervenção pode oferecer, quando e como atuar de forma mais eficiente no suporte ao enlutado.

Quando justifica uma intervenção terciária no suporte ao enlutados, Parkes (2009, p. 283) nos aponta que é possível utilizar dois tipos de orientação técnica em processos de psicoterapia focada no luto, definidas como analítica e paliativa. A intervenção analítica tem como objetivo auxiliar os pacientes a identificar e compreender o padrão de seu mundo presumido e, quando necessário, encontrar um padrão novo para ajustamento às novas condições de vida após a perda. Neste cenário, podem ser usadas tanto as técnicas analíticas como as de natureza mais focada, como terapias breves e de apoio. Vale ressaltar que a técnica 
analítica pode mobilizar intensas reações de angústia, ansiedade e desamparo em um primeiro momento. Para o autor, as técnicas paliativas frequentemente são criticadas pelos analistas por sua natureza objetiva e, por vezes, são tidas como escapistas e superficiais. No entanto, apresentam uma rápida resposta num primeiro momento do processo de luto, pois aliviam a dor psicológica, oferecem amparo e acolhimento para a expressão do pesar, de modo que se tornam fonte de suporte efetivo quando o suporte social é insuficiente.

Neste sentido, conclui-se que uma proposta paliativa seguida por um trabalho analítico iniciado quando o indivíduo já se encontra estabilizado, diante da crise imposta pela perda, é uma estratégia passivel de atingir satisfatoriamente a função do processo de tratamento psicológico. A associação das propostas pode não ser necessariamente relacionada a processos longos de psicoterapia, mas com estratégias bem ajustadas ao processo de luto e às condições de cada enlutado.

Estudos relevantes (Parkes, 1981; Schut e Stroebe, 2005) apontam que quanto mais um enlutado se mostra afetado por fatores de risco no enfrentamento do seu processo, mais evidentes são os benefícios das intervenções focadas no luto. Tal quadro pode estar associado não só às condições do enlutado e da intervenção, mas à quantidade e qualidade metodológica dos estudos de avaliação de eficácia que comprovam estes resultados. Estas pesquisas apontam que as psicoterapias focadas em luto são mais eficazes em seus resultados para os enlutados que estejam enfrentando extraordinário estresse, que apresentam poucos recursos psíquicos de enfrentamento ou com escasso suporte social. Além disso, os resultados positivos parecem estar mais associados às situações nas quais se sentem motivados a procurar ajuda, e por esta razão, estão mais predispostos a confiar no conselheiro ou psicoterapeuta.

\section{As intervenções psicossociais focadas em luto no Brasil}

Este artigo baseou-se em pesquisa bibliográfica que empreendeu um levantamento das intervenções especializadas em luto no Brasil, publicadas em artigos científicos entre 2007 e 2017. Foram encontrados 22 artigos, que possibilitam indicar o perfil das intervenções praticadas no país em diferentes settings e com distintos objetivos. Um quadro resumido, com os resultados obtidos na pesquisa bibliográfica é apresentado abaixo: 
Quadro 2: Resumos dos artigos publicados entre 2007 e 2017 sobre intervenções psicológicas com enlutados no Brasil

\begin{tabular}{|c|c|c|c|c|}
\hline $\begin{array}{c}\text { Ano de } \\
\text { Publicação }\end{array}$ & Título do Artigo & Tipo de Intervenção & $\begin{array}{c}\text { Fundamentação } \\
\text { Teórica }\end{array}$ & $\begin{array}{l}\text { Base de Da- } \\
\text { dos Virtual }\end{array}$ \\
\hline 2007 & $\begin{array}{l}\text { O acompanhamento psico- } \\
\text { lógico a óbitos em unidade } \\
\text { pediátrica (Souza, et al, } \\
\text { 2007). }\end{array}$ & $\begin{array}{l}\text { Intervenção Primária: } \\
\text { acompanhamento psi- } \\
\text { cológico em ambiente } \\
\text { hospitalar }\end{array}$ & $\begin{array}{l}\text { Abordagem psi- } \\
\text { cossocial }\end{array}$ & PePSIC \\
\hline 2007 & $\begin{array}{l}\text { Perda gestacional tardia: } \\
\text { aspectos a serem enfren- } \\
\text { tados por mulheres e con- } \\
\text { duta profissional frente a } \\
\text { essas situações (Carvalho e } \\
\text { Meyer, 2007). }\end{array}$ & $\begin{array}{l}\text { Intervenção Primária: } \\
\text { acompanhamento psi- } \\
\text { cológico em ambiente } \\
\text { hospitalar }\end{array}$ & $\begin{array}{l}\text { Abordagem psi- } \\
\text { cossocial }\end{array}$ & PePSIC \\
\hline 2009 & $\begin{array}{l}\text { Implicações do pronto-a- } \\
\text { tendimento psicológico de } \\
\text { emergência aos que viven- } \\
\text { ciam perdas significativas } \\
\text { (Souza, Moura e Correa, } \\
\text { 2009). }\end{array}$ & $\begin{array}{l}\text { Intervenção secundária } \\
\text { e terciária: acompanha- } \\
\text { mento psicológico em } \\
\text { ambiente hospitalar }\end{array}$ & $\begin{array}{l}\text { Abordagem psi- } \\
\text { cossocial }\end{array}$ & Scielo \\
\hline 2010 & $\begin{array}{l}\text { Caminhos na elaboração de } \\
\text { um luto (Batistelli, 2010). } \\
\end{array}$ & $\begin{array}{l}\text { Intervenção terciária: } \\
\text { Psicoterapia }\end{array}$ & $\begin{array}{l}\text { Abordagem psi- } \\
\text { canalítica }\end{array}$ & PePSIC \\
\hline 2010 & $\begin{array}{l}\text { Luto pela morte de um } \\
\text { filho: utilização de um pro- } \\
\text { tocolo de terapia cogniti- } \\
\text { vo-comportamental (Silva e } \\
\text { Nardi, 2010). }\end{array}$ & $\begin{array}{l}\text { Intervenção terciária: } \\
\text { Psicoterapia }\end{array}$ & $\begin{array}{l}\text { Teoria Cognitivo } \\
\text { Comportamental }\end{array}$ & Scielo \\
\hline 2011 & $\begin{array}{l}\text { Luto e perdas repenti- } \\
\text { nas: contribuições da Te- } \\
\text { rapia Cognitivo-Compor- } \\
\text { tamental (Basso e Wainer, } \\
\text { 2011) }\end{array}$ & $\begin{array}{l}\text { Intervenção terciária: } \\
\text { Psicoterapia }\end{array}$ & $\begin{array}{l}\text { Terapia Cognitiva } \\
\text { Comportamental }\end{array}$ & PePSIC \\
\hline 2011 & $\begin{array}{l}\text { A dor do luto e seu acolhi- } \\
\text { mento psicanalítico (Esther, } \\
\text { 2011), }\end{array}$ & $\begin{array}{l}\text { Intervenção terciária: } \\
\text { Psicoterapia }\end{array}$ & $\begin{array}{l}\text { Abordagem psi- } \\
\text { canalítica }\end{array}$ & PePSIC \\
\hline 2011 & $\begin{array}{l}\text { Intervenção psicológica } \\
\text { em terminalidade e morte: } \\
\text { relato de experiência (Sch- } \\
\text { midt, Gabarra, e Goncalves, } \\
\text { 2011). }\end{array}$ & $\begin{array}{l}\text { Intervenção Primária: } \\
\text { acompanhamento psi- } \\
\text { cológico em ambiente } \\
\text { hospitalar }\end{array}$ & $\begin{array}{l}\text { Abordagem psi- } \\
\text { cossocial }\end{array}$ & Scielo \\
\hline 2011 & $\begin{array}{l}\text { Terapia cognitivo-com- } \\
\text { portamental para luto pela } \\
\text { morte súbita de cônjuge } \\
\text { (Silva e Nardi, 2011a). }\end{array}$ & $\begin{array}{l}\text { Intervenção terciária: } \\
\text { Psicoterapia }\end{array}$ & $\begin{array}{l}\text { Teoria Cognitivo } \\
\text { Comportamental }\end{array}$ & Scielo \\
\hline 2011 & $\begin{array}{l}\text { Terapia cognitivista-com- } \\
\text { portamental para perda } \\
\text { gestacional: resultados da } \\
\text { utilização de um protocolo } \\
\text { terapêutico para luto (Silva } \\
\text { e Nardi, 2011b). }\end{array}$ & $\begin{array}{l}\text { Intervenção terciária: } \\
\text { Psicoterapia }\end{array}$ & $\begin{array}{l}\text { Teoria Cognitivo } \\
\text { Comportamental }\end{array}$ & Scielo \\
\hline
\end{tabular}




\begin{tabular}{|c|c|c|c|c|}
\hline 2012 & $\begin{array}{l}\text { Do luto ao sentido: aportes } \\
\text { da logoterapia no espaço } \\
\text { psicoterapêutico (Corrêa, } \\
\text { 2012). }\end{array}$ & $\begin{array}{l}\text { Intervenção terciária: } \\
\text { Psicoterapia }\end{array}$ & Logoterapia & PePSIC \\
\hline 2012 & $\begin{array}{l}\text { Trabalho em grupo com } \\
\text { enlutados (Pascoal, 2012). }\end{array}$ & $\begin{array}{l}\text { Intervenção secundá- } \\
\text { ria:grupo de apoio aos } \\
\text { enlutados }\end{array}$ & $\begin{array}{l}\text { Psicoterapia de } \\
\text { Grupo }\end{array}$ & Scielo \\
\hline 2013 & $\begin{array}{l}\text { Luto: questões de manejo } \\
\text { técnico na clínica psicanalí- } \\
\text { tica (Gilbran e Peres, 2013). }\end{array}$ & $\begin{array}{l}\text { Intervenção terciária } \\
\text { psicanálise e psicote- } \\
\text { rapias com orientação } \\
\text { psicanalítica }\end{array}$ & Psicanálise & PePSIC \\
\hline 2013 & $\begin{array}{l}\text { Quando a morte visita a } \\
\text { maternidade: atenção psi- } \\
\text { cológica durante a perda } \\
\text { perinatal (Muza et al, 2013). }\end{array}$ & $\begin{array}{l}\text { Intervenção Primária: } \\
\text { acompanhamento psi- } \\
\text { cológico em ambiente } \\
\text { hospitalar }\end{array}$ & $\begin{array}{l}\text { Abordagem psi- } \\
\text { cossocial }\end{array}$ & PePSIC \\
\hline 2013 & $\begin{array}{l}\text { Angústia de uma perda } \\
\text { - caso Maria: uma abor- } \\
\text { dagem terapêutica (Costa, } \\
\text { Mota e Milheiro, 2013). }\end{array}$ & $\begin{array}{l}\text { Intervenção terciária: } \\
\text { Psicoterapia }\end{array}$ & $\begin{array}{l}\text { Abordagem psi- } \\
\text { codinâmica }\end{array}$ & PePSIC \\
\hline 2014 & $\begin{array}{l}\text { Construção de vínculo e } \\
\text { possibilidade de luto em } \\
\text { Unidade de Tratamento In- } \\
\text { tensivo Neonatal (Baltazar, } \\
\text { Gomes e Segal, 2014) }\end{array}$ & $\begin{array}{l}\text { Intervenção Primária: } \\
\text { acompanhamento psi- } \\
\text { cológico em ambiente } \\
\text { hospitalar }\end{array}$ & Psicanálise & PePSIC \\
\hline 2014 & $\begin{array}{l}\text { O processo de luto no } \\
\text { contexto do API-ES: aproxi- } \\
\text { mando as narrativas (Davel } \\
\text { e Silva, 2014). }\end{array}$ & $\begin{array}{l}\text { Intervenção secundária: } \\
\text { grupo de apoio aos en- } \\
\text { lutados }\end{array}$ & Teoria Narrativa & PePSIC \\
\hline 2015 & $\begin{array}{l}\text { Intervenção psicológica } \\
\text { com familiares enlutados } \\
\text { em oncologia pediátrica: } \\
\text { revisão da literatura (Arru- } \\
\text { da-Colli et al, 2015). }\end{array}$ & $\begin{array}{l}\text { Intervenção Primária: } \\
\text { acompanhamento psi- } \\
\text { cológico em ambiente } \\
\text { hospitalar }\end{array}$ & $\begin{array}{l}\text { Abordagem psi- } \\
\text { cossocial }\end{array}$ & PePSIC \\
\hline 2017 & $\begin{array}{l}\text { Profissionais Paliativistas e } \\
\text { suas Contribuições na Pre- } \\
\text { venção de Luto Complica- } \\
\text { do (Braz e Franco, 2017). }\end{array}$ & $\begin{array}{l}\text { Intervenção Primária: } \\
\text { acompanhamento psi- } \\
\text { cológico em ambiente } \\
\text { hospitalar }\end{array}$ & Teoria do Apego & Scielo \\
\hline 2017 & $\begin{array}{l}\text { A escrita como recurso te- } \\
\text { rapêutico no luto materno } \\
\text { de natimortos (Lima e For- } \\
\text { tim, 2017). }\end{array}$ & $\begin{array}{l}\text { Intervenção Primária: } \\
\text { acompanhamento psi- } \\
\text { cológico em ambiente } \\
\text { hospitalar }\end{array}$ & Teoria do Apego & Scielo \\
\hline 2017 & $\begin{array}{l}\text { A Construção do Caso Clí- } \\
\text { nico na Prática Hospitalar: } \\
\text { algumas Reflexões Sobre } \\
\text { Luto e Toxicomania (Silva e } \\
\text { Ulhoa, 2017). }\end{array}$ & $\begin{array}{l}\text { Intervenção Primária: } \\
\text { acompanhamento psi- } \\
\text { cológico em ambiente } \\
\text { hospitalar }\end{array}$ & $\begin{array}{l}\text { Abordagem } \\
\text { Psicanalítica }\end{array}$ & Scielo \\
\hline 2017 & $\begin{array}{l}\text { Apoio psicológico na ter- } \\
\text { minalidade: ensinamentos } \\
\text { para a vida (Oliveira, Santos } \\
\text { e Mastropietro, 2017). }\end{array}$ & $\begin{array}{l}\text { Intervenção terciária: } \\
\text { Psicoterapia }\end{array}$ & $\begin{array}{l}\text { Abordagem Psi- } \\
\text { cossocial e cuida- } \\
\text { dos paliativos }\end{array}$ & Scielo \\
\hline
\end{tabular}

FONTE: Periódicos Eletrônicos em Psicologia (PePSIC). Disponivel em <http://pepsic.bvsalud.org/>. Aces-

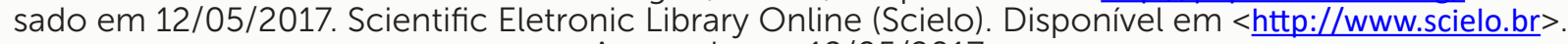
Acessado em 12/05/2017. 
Os resultados desta pesquisa apontam que, das 22 intervenções publicadas, 10 eram sobre intervenções primárias, 3 sobre intervenções secundárias e 9 sobre intervenções terciárias. Sobre as intervenções primárias, duas foram realizadas com fundamentação psicanalítica, cinco com abordagem psicossocial, uma com enfoque sistêmico e duas fundamentadas na "Teoria do Apego". Vale destacar que, entre as abordagens teóricas para compreensão do fenômeno do luto, tanto do ponto de vista intrapsíquico como social, a abordagem da Teoria do Apego (Bowlby, 1944, 1949, 1976, 1982, 1988, 2002[1969], 2004a[1973] e 2004b[1980]) tem sido utilizada como fundamentação para a prática e formação dos profissionais envolvidos, tanto no Brasil como nos Estados Unidos e Inglaterra.

Esta teoria, fundamentada na psicanálise, foi elaborada com base na observação direta do comportamento humano diante de situações de ruptura de vínculo, destacando a importância do sentimento de proteção e reasseguramento em face da ameaça que a distância de uma figura de apego evoca, seja pela separação ou por ruptura definitiva. É uma teoria que oferece um entendimento das reações humanas frente à perda, das condições de enfrentamento do luto, além de fornecer conceitos referentes às condições adaptativas necessárias ao processo de luto para cada indivíduo, considerando aspectos universais e individuais. Esta teoria é amplamente referenciada nas propostas de intervenções com foco no luto (Bromberg, 1995; Parkes, 1998; Bowlby, 1998 e Braz e Franco, 2017).

Retomando a análise dos dados da pesquisa bibliográfica, é importante destacar que todas as intervenções primárias e secundárias apresentadas nos estudos publicados e selecionados para este artigo foram empreendidas em ambiente hospitalar. Dentre as intervenções secundárias, uma utilizou abordagem psicossocial, uma foi baseada em Psicoterapia de Grupo e a terceira em Teoria Narrativa. Nestes casos, o ambiente da intervenção também foi hospitalar. Por fim, das nove intervenções terciárias, três possuíam perspectiva psicanalítica, quatro seguiam o protocolo da Teoria Cognitiva-Comportamental, e as demais baseavam-se na Logoterapia e na Abordagem Psicossocial. Das intervenções pesquisadas, apenas uma, com referencial na Teoria Cognitivo-Comportamental (Silva e Nardi, 2011b), apresentou considerações sobre a eficácia da intervenção, tendo como critério a análise comparativa da evolução dos sintomas entre o início e o fim do tratamento.

Em uma revisão sistemática, efetuada em 2004, Forte, Hill, Pazder e Feudtner encontraram 74 estudos elegíveis, que avaliaram a eficácia de diversos tratamentos designados para o enfrentamento do luto. Entre os estudos, constam a análise de relações terapêuticas estruturadas, intervenções medicamentosas (4), 39 grupos de apoio ou aconselhamento (23, inclusive, grupo controle ${ }^{6}$ e 25 estudos considerando psicoterapias de fundamentação interpessoal, psicanalítica, psicodinâmica e cognitivo-comportamental (17, inclusive, grupo controle). À exceção de tratamentos farmacológicos e tratamentos de luto associado à depressão, os autores não identificaram um padrão consistente de tratamento eficiente, entre

6 Grupo-controle é um grupo de indivíduos que, numa pesquisa científica, não recebem qualquer tratamento especial, a fim de servir como referência-padrão às variáveis a que se submete o grupo experimental. 
as outras formas de intervenção. Como justificativa do resultado apresentado, os autores apontaram cinco fatores que impediram o progresso científico em torno das intervenções com enlutados: 1) excessiva heterogeneidade teórica; 2) invalidação da comparação devido à variação dos estudos; 3) procedimentos de intervenção reportados de forma inadequada; 4) poucas publicações replicando estudos; e 5) falhas metodológicas no projeto dos estudos. Entende-se como falhas metodológicas toda e qualquer condução na coleta e análise dos dados que possam levar a equívocos ou confusões nas análises e resultados apresentados.

\section{Considerações Finais}

A partir de pesquisa bibliográfica apresentada neste artigo, observa-se um número restrito de artigos focados na eficácia das intervenções psicológicas especializadas em luto e publicados nas bases de dados virtuais investigadas (apenas 7\% do total de artigos encontrados). Este dado sugere uma significativa distância entra a prática e a sistematização das pesquisas. Tal panorama pode representar um empecilho para o entendimento das intervenções desenvolvidas até o presente momento, no Brasil, bem como pode não favorecer a formulação de estratégias de intervenção em busca de resultados eficientes junto a enlutados. Conforme mencionado, para aprimorar as intervenções com a população enlutada no Brasil, são necessárias mais pesquisas científicas que possam apontar parâmetros além dos obtidos pela observação clínica. Porém, para uma avaliação da eficácia dessas intervenções, deve-se considerar os seguintes pilares metodológicos: 1) Programas de intervenção empiricamente testados; 2) Pesquisas metodológicas bem desenhadas, que incluam grupos controle; 3) Procedimento de inclusão dos participantes, visando uma avaliação que considere os diversos grupos de enlutados, no que concerne à idade, gênero, tempo de perda, tipo de perda e variáveis socioculturais; e 4) Níveis razoáveis de adesão, para que sejam estudos representativos e suficientes para uma generalização.

A pesquisa bibliográfica realizada evidencia que o ambiente hospitalar tem sido um contexto de crescentes ações preventivas e suportivas para com os enlutados durante o processo de despedida ou logo após a perda. Porém, outros ambientes podem ser considerados, como escolas, postos de saúde, templos religiosos, entre outros, por estarem em condições de acolhimento de ações psicossociais de natureza primária e secundária, realizadas por voluntários e/ou profissionais de saúde e educação. Entretanto, os artigos indicam que há poucas ações nesta direção.

Ainda que seja urgente o desenvolvimento de pesquisas ou protocolos de avaliação da eficácia das intervenções com enlutados, é possível afirmar que estamos na direção correta; buscando terapias que priorizem a expressão emocional, bem como o suporte necessário para que o enlutado se fortaleça para o enfrentamento e adaptação à vida após a perda. Para tanto, devemos considerar a importância do cuidador neste processo; de seu papel e suas 
condições psicológicas para uma efetiva disponibilidade emocional para com os enlutados. Vale lembrar que, por vezes, o psicólogo sente-se mobilizado e/ou identificado com a dor do paciente; o que favorece o risco de comprometimento no cuidado ao enlutado, uma vez que o psicoterapeuta identificado enfrenta o risco de ficar "surdo" e "cego" ao que é essencial do outro. Neste sentido, nunca deve ser um trabalho solitário; fazendo com que supervisão clínica, discussões institucionais dos casos e intervenções realizadas, bem como autocuidado por meio do próprio processo de psicoterapia venham a ser recursos essenciais na preparação do profissional de saúde mental para a realização de um suporte psicológico que seja considerado eficaz e ético. Enfim, o autocuidado do profissional de saúde deve ser considerado necessário para a eficácia do suporte oferecido ao enlutado.

\section{Referências Bibliográficas}

ARIĖS, Philippe. O homem diante da morte. Rio de Janeiro: Francisco Alves, 1977a. 2. Vols. História da morte no Ocidente. Rio de Janeiro: Francisco Alves, 1977b. 312p.

ARRUDA-COLLI, Marina Noronha Ferraz de et al. Intervenção psicológica com familiares enlutados em oncologia pediátrica: revisão da literatura. Psicologia: teoria e prática. São Paulo, vol. 17, n. 2, p. 20-35, Ago, 2015.

BALTAZAR, Danielle Vargas, GOMES, Rafaela Ferreira de Souza e SEGAL, Viviane Lajter. Construção de vínculo e possibilidade de luto em Unidade de Tratamento Intensivo Neonatal. Revista SBPH. Rio de Janeiro, vol. 17, n. 1, p. 88-98, Jun, 2014.

BASSO, Lissia Ana e WAINER, Ricardo. Luto e perdas repentinas: contribuições da Terapia Cognitivo-Comportamental. Revista Brasileira de Terapias Cognitivas. Rio de Janeiro, vol.7, n. 1, p. 35-43, Jun, 2011.

BATISTELLI, Fátima Maria Vieira. Caminhos na elaboração de um luto. Jornal de Psicanálise. São Paulo, vol. 43, n. 79, p. 155-162, Dez, 2010.

BOWLBY, John. Forty-four juvenile thieves: their characters and home-life. International Journal of Psychoanalysis, v. 25, p. 19-53, 1944. 123-8, 1949.

The study and reduction of group tensions in the family. Human Relations, v. 2, p.

Attachment and loss: Attachment. New York: Basic Books, v. I, 1969. [Edição Brasileira: BOWLBY, John. Apego e Perda: a natureza do vínculo. São Paulo: Martins Fontes, 2002].

Attachment and loss: Separation: anxiety and anger. New York: Basic Books, v.

II, 1973. [Edição Brasileira: BOWLBY, John. Apego e perda: separação, angustia e raiva. São 
Paulo: Martins Fontes, 2004a].

Child care and the growth of love. London: Penguin Books, 1976. 256p.

Attachment and loss: Loss: sadness and depression. New York: Basic Books, v. III, 1980. [Edição Brasileira: BOWLBY, John. Apego e perda: tristeza e depressão. São Paulo: Martins Fontes, 2004b]

Cuidados Maternos e Saúde Mental. São Paulo: Martins Fontes, 1981. 239p.

Formação e rompimento dos laços afetivos. São Paulo: Martins Fontes, 1982. 228p.

A secure base: parent-child attachment and healthy human development. New York: Basic Books, 1988. 416p.

BRAZ, Mariana Sarkis; FRANCO, Maria Helena Pereira. Profissionais Paliativistas e suas Contribuições na Prevenção de Luto Complicado. Psicologia: Ciência e profissão. Brasília, v. 37, n. 1, p. 90-105, Jan, 2017. Disponível em <http://www.scielo.br/scielo.php?script=sci_ arttext\&pid=S141498932017000100090\&lng=en\&nrm=iso>. Acesso em 12/05/2017. DOI: http://dx.doi.org/10.1590/1982-3703001702016.

BREEN, Lauren J; PENNAN, Emma L.; PRIGERSON, Holly G.; HEWITT, L. Y. Can Grief be a Mental Disorder?: An Exploration of Public Opinion. The Journal of Nervous and Mental Disease, v. 203, n. 8, p. 569-573, August, 2015.

BROMBERG, Maria Helena Pereira Franco. Psicoterapia em situações de perda e luto. Campinas: Editorial Psy, 1995. 160p.

CARVALHO, Fernanda Torres de e MEYER, Laura. Perda gestacional tardia: aspectos a serem enfrentados por mulheres e conduta profissional frente a essas situações. Boletim de Psicologia, vol. 57, n. 126, p. 33-48, Jun, 2007.

CASELLATO, Gabriela (org.). Dor Silenciosa ou dor silenciada? Perdas e lutos não reconhecidos por enlutados e sociedade. São Paulo: Ed. Polo Books, 2013. 158p.

O Resgate da Empatia: suporte psicológico ao luto não reconhecido. São Paulo: Summus Editorial, 2015. 264p.

FRANCO, Maria Helena; MAZORRA, Luciana; TINOCO, Valéria. Luto Complicado: considerações para a prática. In: SANTOS, Franklin Santana (org.). A Arte de morrer: visões plurais. São Paulo: Comenius, v. 2, 2009. 272p.

CORRÊA, Diogo Arnaldo. Do luto ao sentido: aportes da logoterapia no espaço psicoterapêutico. Psicologia: teoria e prática. São Paulo, vol. 14, n. 3, p. 180-188, Dez, 2012.

COSTA, Mônica; MOTA, Catarina Pinheiro; MILHEIRO, Cláudia. Angústia de uma perda - caso Maria: uma abordagem terapêutica. Psicologia Clínica. [online] vol. 25, n. 2, p. 197-213, Jun. 2013.

DAVEL, Alzira da Penha Costa e SILVA, Daniela Reis. O processo de luto no contexto do APIES: aproximando as narrativas. Pensando Famílias, vol. 18, n. 1, p. 107-123, Jun., 2014. 
DOKA, Keneth. Introduction. In: DOKA, Keneth. Disenfranchiesed Grief: New Directions, Challenges and Strategies for practice. Illinois: Research Press, p. 5-20, 2002a.

MARTIN, T. How we Grieve: Culture, Class and Gender. In: DOKA, Keneth (org.). Disenfranchised Grief: New Directions, Challenges and Strategies for Practice. Illinois: Research Press, p. 337-347, 2002b.

ESTHER, Vera. A dor do luto e seu acolhimento psicanalítico. Estudos de Psicanálise [online]. n. 35, p. 151-165, Jul, 2011.

FORTE, A.; HIL, L.; M. PAZDER. \& R. FEUDTNER, C. Bereavement care intervention: a systematic review. BMC Palliative Care, vol. 26, n. 3, jul, 2004.

FRANCO, Maria. Helena. Pereira. Porque estudar luto na atualidade. In: Formação e rompimento de vínculos: o dilema de perdas na atualidade. São Paulo: Summus, p. 17-42, 2010.

O luto como experiência vital. Disponível em <http://www.4estacoes.com/pdf/ textos_saiba_mais/luto_como_experiencia_vital.pdf>. Acesso em 13/05/2017.

FREUD, Sigmund. Mourning and melancholia. The Standard Edition of the Complete Psychological Works of Sigmund Freud. Londres: Hogard, 1953 [1917].

GIBRAN, Renata Cristina Ribeiro e PERES, Rodrigo. Luto: questões de manejo técnico na clínica psicanalítica. Revista da SPAGESP (online), vol. 14, n. 2, p. 73-85, 2013.

KERSTING A.; BRATHLER E.; GLAESMER H; WAGNER B. Prevalence of complicated grief in a representative population-based sample. J. Affect Disorders 131 (1-3), p. 339-343, jun, 2011.

KISSANE, David W.; PARNES, Francine (ed.). Bereavement Care for Families. New York; London: Routledge, 2014. 294p.

KLASS D.; WALTER, T. Processes of grieving: how bonds are continued. In: STROEBE, Margareth; HANSSON, Robert; STROEBE, Wolfgang; SCHUT, Henk (org.). Handbook of Bereavement Research: consequences, coping and care. Washington: American Psychological Association, p. 431-448, 2001.

LABATE, Renata Curi e BARROS, Gisele Curi de. Uma possibilidade de escuta a uma família enlutada: ressignificando a experiência de perda. Revista da SPAGESP, vol. 7, n. 1, p. 50-57, Jun, 2006. Disponível em: <http://pepsic.bvsalud.org/scielo.php?script=sci_ arttext\&pid=S1677-29702006000100007>. Acesso em 19/04/2017.

LICHTENTHAL W, et al. Mental Health Servicer for Parents Who Lost a Child to Cancer: If We Build Them, Will They Come?. Journal of Clinical Oncology. New York, vol. 33, n. 20, p. 22462253, july 2015.

LIMA, Sabrina e FORTIM, Ivelise. A escrita como recurso terapêutico no luto materno de natimortos. Revista Latinoamericana de Psicopatologia Fundamental. São Paulo, v. 18, n. 4, p. 771-788, 2015. Disponível em <http://www.scielo.br/scielo.php?script=sci_ arttext\&pid=S141547142015000400771\&lng=en\&nrm=iso>. Acessado em 12/05/2017. DOI: http://dx.doi.org/10.1590/1415-4714.2015v18n4p771.12 
LINDEMANN, Erich. The Symptomatology and management of acute grief. American Journal of Psychiatry, v. 101, no 2, September, p. 141-148, 1944.

LOMBARDO, L. et al. Bereavement and complicated grief: towards a definition of Prolonged Grief Disorder for DSM-5. Rivista di Psichiatria, 49 (3), p. 106-114, May-Jun, 2014. DOI: 10.1708/1551.16903.

MUZA, Júlia Costa; SOUSA, Erica Nascimento de; ARRAIS, Alessandra da Rocha e IACONELLI, Vera. Quando a morte visita a maternidade: atenção psicológica durante a perda perinatal. Revista Psicologia: Teoria e Prática. vol. 15, n. 3, p. 34-48, Dez, 2013.

NADEAU, Janice. Families making sense of death. Califórnia: Sage Publications, 1997. 289p.

NEIMEYER, Robert (ed.). Meaning Reconstruction and the experience of loss. Washington DC: American Psychological Association, 2001. 359p.

OLIVEIRA, Érika Arantes de; SANTOS, Manoel Antônio dos e MASTROPIETRO, Ana Paula. Apoio psicológico na terminalidade: ensinamentos para a vida. Psicol. Estud. Maringá, v. 15, n. 2, p. 235-244, Jun, 2010. Disponível em: <http://www.scielo.br/scielo.php?script=sci_ arttext\&pid=S141373722010000200002\&lng=en\&nrm=iso>. Acesso em 12/05/2017. DOI: http://dx.doi.org/10.1590/S1413-73722010000200002.

PARKES, Colin Murray. Evaluation of bereavement Services. Journal of Preventive Psychiatry 1(2), p. 179-188, 1981.

Luto. Estudos sobre a perda na vida adulta. São Paulo: Summus, 1998. 290p.

A Historical Overview of the Scientific Study of Bereavement In: STROEBE, Margareth; HANSSON, Robert; STROEBE, Wolfgang; SCHUT, Henk (org.). Handbook of Bereavement Research: consequences, coping and care. Washington: American Psychological Association, p. 25-46, 2001.

Symposium on Complicated Grief. OMEGA: Journal on Death and Dying. New York, v. 52, n 1, p 1-7, 2005-2006a.

$448 p$.

Amor e Perda: as raízes do luto e suas complicações. São Paulo: Summus, 2009.

(ed.). Responses to Terrorism: Can psychosocial approaches break the cycle of violence? UK; New York: Routledge Hove, 2014. 280p.

$2015 a$

The Price of Love: the select works of Colin Murray Parkes. Londres: Routledge,

The Price of Love: The Selected Works of Colin Murray Parkes. UK \& New York: Routledge, Hove, 2015b.

; LAUNGANI Pittu \& YOUNG, Bill. (ed.). Death and Bereavement Across Cultures. London; NY: Routledge, 2015c [1996]. 272p.

PASCOAL, Melissa. Trabalho em grupo com enlutados. Psicol. Estud. Maringá, v. 17, n. 
4, p. 725-729, Dec, 2012. Disponível em <http://www.scielo.br/scielo.php?script=sci= arttext\&pid=S141373722012000400019\&lng=en\&nrm=iso>. Acessado em 12/05/2017. DOI: http://dx.doi.org/10.1590/S1413-73722012000400019.

RANDO, Therese A. Theories of complicated mourning: a historical review in treatment of complicated mourning. Champaign: Research Press, 1993. 751p.

SCHMIDT, Beatriz; GABARRA, Letícia Macedo; GONCALVES, Jadete Rodrigues. Intervenção psicológica em terminalidade e morte: relato de experiência. Paidéia (Ribeirão Preto). Ribeirão Preto, v. 21, n. 50, p. 423-430, Dec. 2011. Disponível em <http://www.scielo.br/ scielo.php?script $=$ sci_arttext\&pid $=$ S0103863X2011000300015\&lng $=$ en\&nrm=iso>..$\quad$ Acesso em 12/05/2017. http://dx.doi.org/10.1590/S0103-863X2011000300015.

SCHUT, Henk \& STROEBE, Margareth. Interventions to Enhance Adaptation to Bereavement. Journal of Palliative Medicine. Volume 8, Supplement 1, 2005, p 141-148.

SILVA, Adriana Cardoso de Oliveira e NARDI, Antonio Egidio. Luto pela morte de um filho: utilização de um protocolo de terapia cognitivo-comportamental. Revista de psiquiatria do Rio Grande do Sul. Porto Alegre, v. 32, n. 3, p. 113-116, 2010. Disponível em <http://www.scielo.br/ scielo.php? script $=$ sci_arttext\&pid $=S 010181082010000300008 \& \operatorname{lng}=$ enfnrm $=i s o>$. Acessado em 12 de maio de 2017. DOI: http://dx.doi.org/10.1590/S0101-81082010000300008.

e _-__-_. Terapia cognitivo-comportamental para luto pela morte súbita de cônjuge. Revista de Psiquiatria Clínica. São Paulo, v. 38, n. 5, p. 213 215, 2011a. Disponível em: <http://www.scielo.br/scielo.php?script=sci_ arttext\&pid=S010160832011000500010\&lng=en\&nrm=iso>. Acessado em 12/05/2017. DOI: http://dx.doi.org/10.1590/S0101-60832011000500010.

e Terapia cognitivista-comportamental para perda gestacional: resultados da utilização de um protocolo terapêutico para luto. Revista de Psiquiatria Clínica. São Paulo, v. 38, n. 3, p. 122-124, 2011b. Disponível em: <http://www.scielo.br/scielo.php? script=sci_ arttext\&pid=S010160832011000300007\&lng=en\&nrm=iso>. Acessado em 12/05/2017. DOI: http://dx.doi.org/10.1590/S0101-60832011000300007

SILVA, Michelle Karina; ULHOA, Arthur Pizani. A Construção do Caso Clínico na Prática Hospitalar: algumas Reflexões Sobre Luto e Toxicomania. Psicologia: Ciência e profissão. Brasília, v. 35, n. 2, p. 503-514, June, 2015. Disponivel em <http://www.scielo.br/scielo.php?script=sci_ arttext\&pid=S141498932015000200503\&lng=en\&nrm=iso>. Acesso em 12/05/2017. DOI: http://dx.doi.org/10.1590/1982-370300292014

SOUZA, Airle Miranda de; MOURA, Danielle do Socorro Castro e CORREA, Victor Augusto Cavaleiro. Implicações do pronto-atendimento psicológico de emergência aos que vivenciam perdas significativas. Psicologia: Ciência e profissão. Brasília, v. 29, n. 3, p. 534545, 2009. Disponível em <http://www.scielo.br/scielo.php?script=sci_arttext\&pid=S141498932009000300008\&lng=engnrm=iso>. Acesso em 12/05/2017. DOI: http://dx.doi. org/10.1590/S1414-98932009000300008

STEVENSON-HINDE, Joan; MARRIS, Peter; PARKES, Colin Murray (ed.). Attachment Across the Life Cycle. London \& NY: Routledge, 1991. 320p.

STROEBE, Margareth; SCHUT, Henk. The dual process model of bereavement: rationale and 
description. Death studies. Philadelphia, v. 23, p. 197-224, 1999.

Meaning making in the dual process model of coping with bereavement. In: NEIMEYER, Robert (org.). Meaning Reconstruction and the experience of loss. Washington DC: American Psychological Association, 2001.

A conceptual analysis of the field. Omega: Journal on Death and Dying, New York, v. 52, n. 1, p. 53-70, 2005-2006.

Recebido em: 13 de março de 2017

Aprovado em: 30 de maio de 2017 